\title{
Applicative Research on Psychological Demand of Audience and the TAXI for People
}

\author{
Caixia Zhang \\ Wuhan Donghu University, 430012 Wuhan Hubei, China
}

\begin{abstract}
Whether TAXI for People from Beijing traffic channel, the only special program customized for taxi driver in Beijing, knows about the psychological feature of the certain taxi group is an important factor that affects the development of program. Based on demand theory of psychology, this article uses the questionnaire method to find out the psychological feature and lifestyle of audience, and discusses the degree to the TAXI for People which meets the psychological demand of taxi driver audience by analysis on the program content. It is said from the research that the TAXI for People basically meets the psychological demand from taxi drivers. However, this program shall focus more on their basic needs and provide the opportunity for the audience to participate in the program and activity.
\end{abstract}

Keywords. traffic radio station; TAXI for People; Maslow Hierarchical Theory of Demand

\section{Introduction}

On Sept. 30, 1991, the traffic information station in Shanghai People's Radio Station officially launched and became the start for the growth of Chinese traffic radio. Thereafter, the radio stations from other places successively followed this behavior by opening their own traffic channels. One of the important features for the traffic radio is to take the traffic participators as the communication objective. The taxi driver is an important participator in the traffic and the long-term loyal audience for the traffic radio station.

The TAXI for People in Beijing traffic station is a special program customized for taxi drivers. Its frequency modulation is 103.9, the broadcasting time is from 11:30 to 12:00 every noon, and the rebroadcasting time is from 1:30 to 2:00 at midnight. The program is to focus on the life and work for taxi drivers, and it has formed a steady audience group of the taxi drivers and their families in Beijing since it started in 2001.

Based on the demand theory of psychology, this article uses quantitative research method to analyze the degree to which TAXI for People meets the psychological demand of taxi driver audience. First, it makes an analysis on the content of TAXI for People to know about the topic distribution feature and tendency of this program; second, it uses questionnaire based on which judges the degree to the TAXI for People which meets the 
psychological demand of taxi driver audience to know about the audience behavior and the psychological demand of taxi driver in Beijing.

\section{Summary of theory}

The American psychologist Maslow released A Theory of Human Motivation in 1943 when the "Hierarchical Theory of Demand" was proposed and he thought that human has five basic demands: the physiology, the safety, the love and belonging, the respect and the selfrealization.

Maslow thought that the food, domicile, health and other physiological demand are the most basic and primarily produced needs. The safety demand is produced as the physiological demand for individual who is relatively and fully satisfied. The safety demand includes the danger avoidance and the life security, and it is characterized by professional stability, deposit, social security and so on. As the physiological demand and the safety demand are well satisfied, the love and belonging demand will be produced and one will be eager for other people's care and love, as well as hope to become one of the group and establish an excellent interpersonal relationship. The respect demand includes self-esteem and respect from others. On one hand, we hope to get attention, care and recognition from others and request for reputation, prestige and status; on the other hand, we hope to have strength, achievement and confidence. The self-realization demand belongs to the top-leveled demand referring to "a tendency to realize its potential". This tendency may be characterized by eagerness for one wants to have his original human status and hopes to realize the human's potential. ${ }^{[1]}$

In the Hierarchical Theory of Demand from Maslow, people's demand is interrelated and overlapped with hierarchy. A higher demand will appear only if the low-leveled demand is basically satisfied, and the demand for self-realization will appear only if all the demands are successively satisfied. Furthermore, "human will have multiple demands at the same time, place and condition, one of which taking a dominant position determines the human behavior." ${ }^{2}$ Therefore, the Hierarchical Theory of Demand of Maslow is a theory to predict the behavior probability, and the categorization of this demand indicates a basic tendency.

\section{Research methods}

This article mainly uses the research method of questionnaire and content analysis based on which judges the degree to which TAXI for People meets the psychological demand of taxi driver audience to analyze the content of TAXI for People and psychological feature of taxi drivers. Also, it proposes constructive opinions on the development of program.

The investigated objective of this research includes the taxi driver in the taxi company registered in Beijing City. Considering the big difference in nature, the scale of taxi companies in Beijing, and the convenience of sampling, we use the cluster-sampling method for a squad in taxi companies during this investigation. We randomly pick 3 taxi companies in Beijing, and pick out one squad in each company, namely 200 samples in total. Then 173 valid questionnaires are finally recovered.

The sampling is conducted when $95 \%$ of confidence interval and $7 \%$ of error level are ensured. This investigation result can be statistically used to predict the overall conditions of taxi in Beijing and it has some practical meaning.

To understand the relevant demand and degree of taxi driver in Beijing, the author prepares an investigation scale of psychological demand for taxi driver in Beijing based on trial investigation on 50 samples, and remedies and complements the original questionnaire, 
as well as uses project analysis and factor analysis for credibility and validity inspection on the scale. The result of credibility detection indicates a good credibility of demand hierarchy scale. In the modified psychological demand scale, the Alph factor is 0.8438 , KMO 0.852.

The demand hierarchy scale totally includes 30 items, and uses five-level grading: 1 point for being non-important; 2 points for being not so important; 3 points for being not important; 4 points for being relatively important, and 5 points for being very important. The scale includes seven dimensions for demand: physiological demand, safety demand, love and belonging, respect and self-realization. The dimensions of these five demands also include several sub-factors.

The content analysis part mainly reads the text in TAXI for People to know about the type and focus of TAXI for People. As the program group of TAXI for People only keeps $\mathrm{CD}$ for few episodes, the author himself recorded three-month program and obtained 56 valid texts. Due to limited samples and restrictions for sampling, this article conducts an overall survey on the samples.

\section{Conclusion analysis}

Among 173 taxi drivers in Beijing in this sampling investigation, the oldest is 53 years old, and the youngest is 23 years old. There are 165 Males, 3 females and 5 people are missed.

Table 1. Diploma of taxi driver

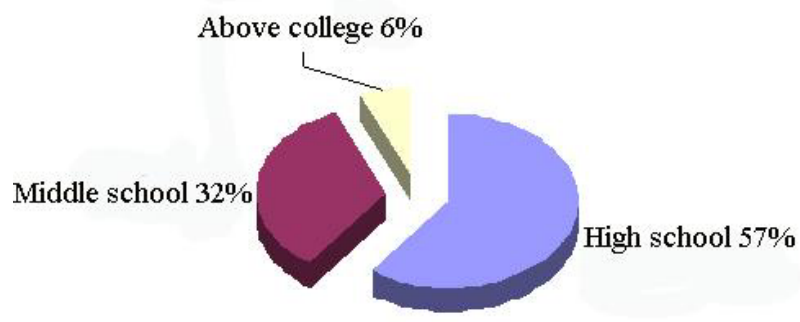

The taxi drivers with high school diploma have the largest proportion and they account for $57 \%$, namely 98 people in total; taxi drivers with middle school diploma account for $32 \%$, namely 55 people in total; while the taxi drivers with college and above diploma only account for $6 \%$, namely 6 in total.

It is indicated from the investigation result that the reasons for Beijing taxi drivers to be audience for TAXI for People are respectively: 50\% to understand the road traffic information; $47 \%$ to communicate with other drivers; $45 \%$ to know about the industrial dynamics; $31 \%$ to abate the fatigue; others to obtain the knowledge and love the host. Most of taxi drivers have a great overall assessment and high belongings for the program, and the host Yang Li enjoys much public praise among the audience.

\subsection{Analysis on psychological demand of taxi drivers}

According to the data of psychological demand scale, this part will conduct a comparison and analysis on the psychological demand, safety demand, love and belonging demand, respect demand and self-realization demand for taxi driver in Beijing.

\subsubsection{The demands of taxi driver in Beijing in each hierarchy are at a high level}


The score of five demands that are respectively psychological demand, safety demand, love and belonging demand, respect demand and self-realization demand centers around 4-5 points in the range of being relatively demanded and extremely demanded. Among these samples, the demands of taxi driver in Beijing in each hierarchy are at a high level.

\subsubsection{The advantageous demand for taxi driver is basic}

In the samples, the physiological, safety, love and belonging demands for taxi driver are the most important demands, and the scores of importance are all above 4.5 points. It is related to living conditions for taxi driver. Taxi drivers almost spend the whole day in cars. Timely meal, sufficient sleep and other basic demands are luxuries for them. Thus, high-strength and long-term operation inflict cervical spondylosis, lumbar muscle strain, stomach and other diseases on taxi drivers.

Table 2. Reason to be audience of the taxi program

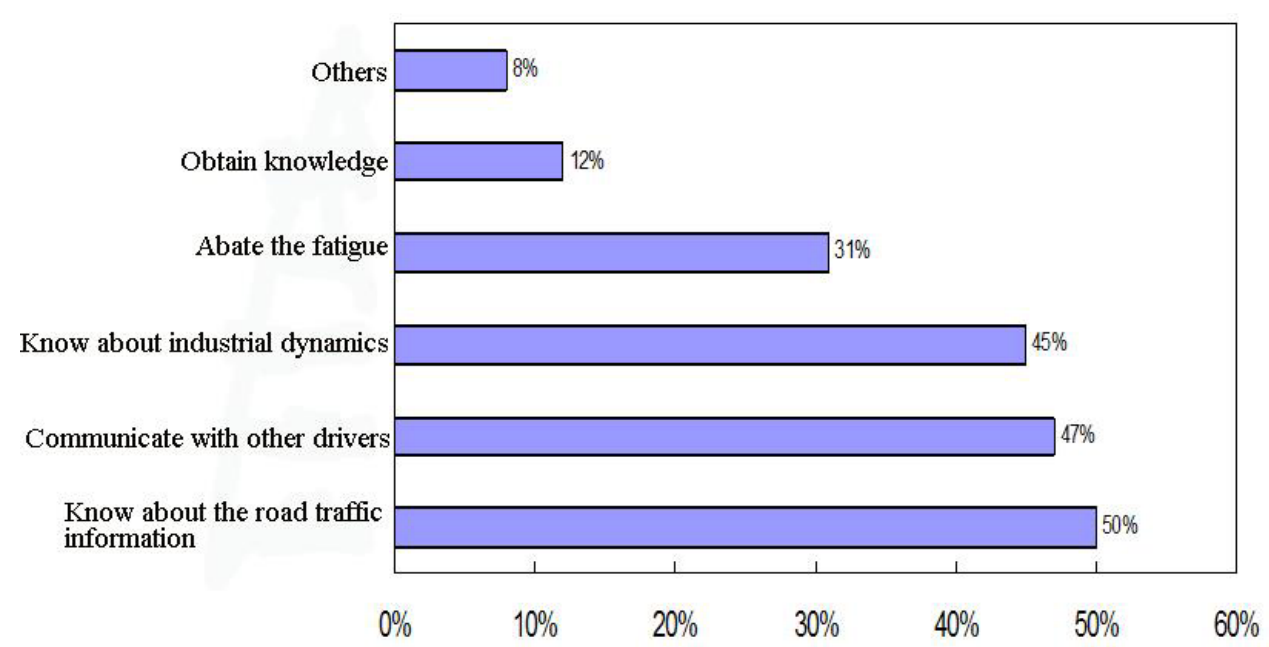

Table 3. Psychological demand of taxi drivers

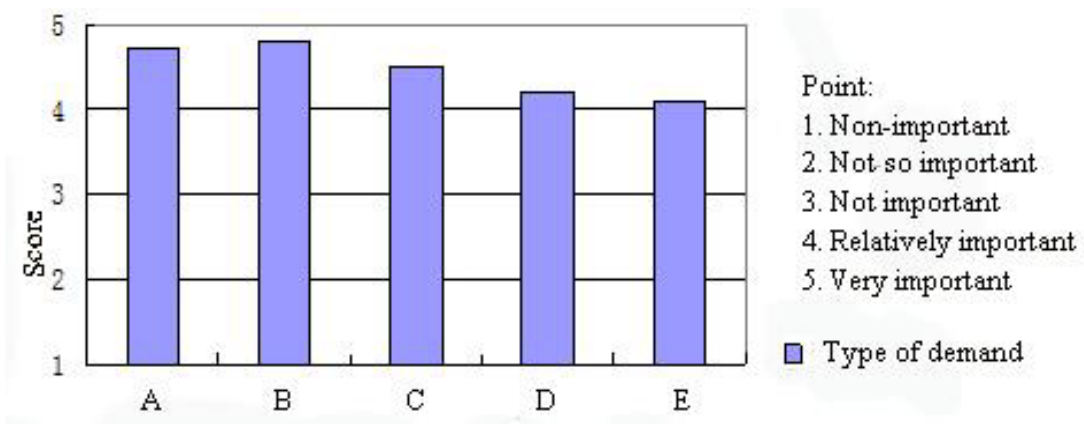

A: Physiological demand; B: Safety demand; C: Love and belonging demand; D: Respect demand; E: Self-realization demand

4.1.3 Safety demand is what the taxi drivers attach most importance to. 
In the rank of demands most urgent to be satisfied, the demands ranking top five are respectively excellent social security, body health, family stability, sufficient sleep and conjugal affection. It can be seen that the safety demand is what the taxi drivers attach most importance to. The taxi drivers are all involved in their risky "one man with one car" operation alone. In recent years, the news about taxi driver was frequently seen in the headings of newspaper. Excellent security environment appears to be very important for them. Furthermore, the importance the taxi driver attaches to safety demand is related to imperfect Chinese insurance system and relatively low income.

\subsubsection{The demand in high hierarchy is focused on, but the demands are lower than the demand in low hierarchy}

The respect and self-realization, as the demands in relatively high hierarchy, are also focused on by taxi drivers, but the result tends to be "relatively important". Due to limited living conditions, they focus more on demands in low hierarchy.

\subsection{Analysis on program content}

The TAXI for People has "Driver Talk Show", "Driver Magpie Bridge", "On-line Charming Leader", "Driver Gym", "Driver's Station Agent", "Driver Takes You to Travel in Beijing", "Driver's Legal Aid Station", and "Driver Service Hot Line" and other programs. It is indicated from the analysis on content of TAXI for People that the program covers life and work of taxi driver, including knowledge of health, knowledge of laws, operation, life, and mutual assistance of drivers and so on. The program takes into account the demands in low and high hierarchy for taxi driver. Considering the busy work, common occupational diseases, limited economic level and other features for taxi drivers, the TAXI for People appeals for drivers to focus on health and insists on organization of free body inspection, family travel and sports for them, which provides care for life of taxi driver beyond the program.

\subsection{Conclusion}

The taxi driver group has a low income and social status, and their work is risky. They are eager to have safety, physiological and other demands in low hierarchy satisfied prior to those of respect, self-realization and other demands in high hierarchy.

In addition to focus on demands in low hierarchy for taxi driver, the TAXI for People satisfies the view of audience and meets their spiritual pursuit in high hierarchy by soul talk and establishing excellent driver image and organization of foreign travel.

It can be seen that the TAXI for People basically meets the psychological demand for taxi driver and it is a radio program with accurate positioning and rich content.

\section{Suggestions}

1. Solving actual problems for taxi driver: The TAXI for People has a high reputation and recognition for taxi driver group. Most of taxi drivers think the program is conducive to their work and life and it can increase their confidence and view. But in the suggestions about the program, some taxi driver audiences hope that the TAXI for People shall "tend to consider the actual conditions for target" and be able to help them solve "reducing common charges of taxi", legal rights maintenance and other actual problems in a better way. Of 
course, the media cannot replace the governmental function, but it can facilitate the problem solution by report and appeal.

2. Focus more on demands in low hierarchy: The economic income and social status for taxi driver is low, so the physiological, safety and other demands in low hierarchy shall be firstly satisfied. The "Driver Magpie Bridge", "Driver Gym", "Driver Service Hot Line" and other programs will help taxi driver solve actual problems in marriage, health, life, and so on, and meet the demands in low hierarchy for audience.

3. More opportunity for taxi driver to talk: The practicality is one of the important reasons for taxi driver to be audience of the TAXI for People. The road traffic information obtained from the program and communication among drivers are helpful to operation. The TAXI for People may have a better communication with audience by increasing the broadcast time. Furthermore, it may invite more taxi drivers to be the guests in the program to increase their sense of belonging.

4. Insisting on organization of activity for taxi driver: Yang Li, the host of TAXI for People, communicates with audience in the program and also positively organizes various "foreign travel" and "family travel" activities to have a close connection with taxi driver. The TAXI for People also supports the establishment of Beijing loving drivers team, Beijing female loving drivers team, 1039 driver gallery, Beijing driver art group and other organizations to advocate healthy lifestyle and increase the group cohesion and professional pride for taxi drivers. These activities have obtained unanimous praise from drivers and enriched the spare-time life for them. The TAXI for People is also called "a warm home for drivers".

5. Extension of program time: The TAXI for People is a broadcast for just half an hour, and many taxi drivers think it's a little too short. Especially in the talking section, there is not less than one guest, each having little time to say something. Furthermore, it's a broadcast exactly at noon when many drivers miss the program due to lunch, which causes audience drain. The program time could be properly extended to meet the demand of audience.

\section{References}

1. Maslow. Cheng, M. tran., 2003. Maslow Humanistic Philosophy. Beijing: Jiuzhou Press, pp: 57.

2. Shi, R.H. 2003. Modern Social Psychology. Shanghai: East China Normal University Press, pp: 179. 